\title{
Hygiene behavior in face of the corona pandemic: Compliance rates and associations with fear, SARS-COV-2 risk, mental health and disability
}

\author{
Sonia Lippke ${ }^{1,}$, Franziska M. Keller ${ }^{2}$, Christina Derksen ${ }^{3}$, Lukas Kötting ${ }^{4}$ and Alina Dahmen ${ }^{5}$ \\ 1 Department of Psychology \& Methods, Jacobs University Bremen, Bremen 28759, Germany \\ 2 Department of Psychology \& Methods, Jacobs University Bremen, Bremen 28759, Germany; f.keller@jacobs- \\ university.de \\ 3 Department of Psychology \& Methods, Jacobs University Bremen, Bremen 28759, Germany; c.derksen@ja- \\ cobs-university.de \\ 4 Department of Psychology \& Methods, Jacobs University Bremen, Bremen 28759, Germany; 1.koetting@ja- \\ cobs-university.de \\ 5 Dr. Becker Klinikgruppe, Köln 50968, Germany; adahmen@dbkg.de \\ * Correspondence: s.lippke@jacobs-university.de; Tel.: +49/421/2004730
}

\begin{abstract}
Background: During the COVID-19 pandemic, hygiene behaviors such as keeping distance, avoiding masses, wearing face masks and adhering to hand hygiene recommendations became imperative. The current study aims to determine factors interrelating with hygiene behaviors. Methods: 4,049 individuals (1,305 male, 2,709 female, aged 18-80 years) were recruited from rehabilitation clinics or freely on the internet and surveyed via online questionnaire between May 2020 and August 2021. Socio-demographics, hygiene behaviors, emotions (fear), life-satisfaction, risk factors and disability as well as communication were assessed. Results: Prevalence for hygiene behaviors was: keeping the distance $84.9 \%$, avoiding mass gatherings $84.6 \%$, wearing face masks $96.5 \%$ and hand hygiene $80.7 \%$. Hygiene behaviors were significantly related to fear with linear and quadratic associations. Conclusion: Individuals with disabilities, risk factors and psychological symptoms are more compliant. Especially hand hygiene should be targeted to achieve higher compliance rates. A medium level of fear is more functional than too elevated fear. Behavioral interventions and targeted communication aiming at improving different behaviors in orchestration can help individuals to remain healthy and maintain a high life-satisfaction. Thereby, communication in the healthcare setting is imperative and all involved individuals should become more aware of this to ensure high hygiene standards and patient safety.
\end{abstract}

Keywords: COVID-19; disability; risk factors; communication; medical rehabilitation; psychosomatic patients; general public; infection; physical health; psychological health

\section{Introduction}

The prevention of communicable diseases and infections is key for population health and protecting the health of susceptible populations [1]. This becomes especially clear during the COVID-19 pandemic with the risk of transmissions from human to human [2]. Hygiene behaviors are not new, but during the corona pandemic, the whole population was required to perform behaviors such as:

- Keeping the distance of $1.5 \mathrm{~m}$ between humans,

- Avoiding mass gatherings,

- Wearing face masks,

- Adhering to hand hygiene requirements [3].

With the first three behaviors required by law in Germany at most times during the pandemic, hand hygiene is being recommended and enforced by policies for institutions 
such as hospitals, senior homes and care homes for susceptible populations [4] but not by law on the population level. These measures were aimed at reducing the spread of the virus through person-to-person contact. The COVID-19 pandemic led governments and responsible parties, as well as mass communication and the press to communicate these behaviors in many countries, including Germany $[5,6]$ and to ensure patient safety. Accordingly, it was often found that the level of fear, worry or concern of own risk of SARS-CoV-2 infection was interrelated with the prevalence of frequent hand hygiene $[7,8]$ but not with physical distancing, leaving home for food or to exercise [7]. Also, the fear of becoming seriously ill with COVID-19 was correlated with behavior change [9]. Vulnerability, perceived risk, and fear were all found to be significantly interrelated with preventive behaviors during the coronavirus pandemic [10]. On the contrary, one study revealed no correlation of health-protective behavior with fear during the beginning of the COVID-19 pandemic [3].

However, hygiene behavior does not only affect the spread of the SARS-CoV-2 virus but also other viruses, bacteria and parasites [2]. Thus, while we can learn from the past with campaigns preventing the spread of, e.g., hospital transmissions and hospital-acquired infections (HAIs; [11]), many people now learned about these hygiene behaviors who may have not been vulnerable or aware before. Thus, hygiene has also come into focus among people who previously had no awareness or knowledge in infection prevention: the COVID-19 pandemic has changed many life areas, and directly or indirectly impacted everyone worldwide. It evolved emotions (such as fear; [12]), which were intentionally addressed by the media and social environment [13]. Especially in vulnerable groups, the Covid-19 pandemic increased existing fear [14,15]. It is well known from the findings of the influenza A pandemic that increased media coverage leads to an increase in anxiety [16]. The question, however, is whether a pronounced risk communication that induces fear in individuals is actually related to more hygiene behavior.

While people with risk factors for COVID-19 have received considerable early attention (e.g. $[2,17])$, less attention has been paid to other susceptible populations i.e. individuals with previous mental or physical comorbidities and disabilities [18]. Although increasingly systematic research is now available on risk factors causing a severe course of COVID-19 (like cardiovascular disease, diabetes, respiratory illnesses, liver disease, kidney disease or cancer) [19], and the knowledge that people with disabilities have more barriers to perform hygiene behavior [20], rather little is known about the differences between people with disabilities and individuals with risk factors - which is why this study will examine the issue in more detail. What is known from before is the following: Patients with (pulmonary) comorbidities i.e. corona risk factors report significantly higher fear levels than those without comorbidities [17]. Whether and how this is related to disability and mental health remains unclear right now. In the following, fear and mental health will be reviewed accordingly to lay the basis for the current study.

Over the course of the pandemic, several researchers have examined the link between the fear of infection, enforced isolation and mental health symptoms. It was generally found that fear and uncertainty led to higher levels of anxiety and depression [21,22]. Especially in vulnerable populations who were susceptible or already suffering from mental health problems, social isolation and loneliness were responsible for substantially higher rates of mental health problems [23,24]. Additionally, people with intellectual disabilities were more likely to be infected with COVID-19 compared with the average regional population $(0.32 \%$ vs. $1.87 \%)$. Alarmingly, people with intellectual disabilities were more likely to have died from COVID-19 (0.015\% vs. 0.10\%; [25]). Accordingly, a question that arises based on the previous findings is the following:

Research Question 1. Do differences between individuals from the general population and from a sample of patients with mental health problems with disabilities or with COVID-19 risk factors 
emerge in terms of (a) hygiene behaviors and (b) fear of infection as well as (c) health and life-satisfaction?

\section{Relationship between Covid-19 related fear and behavior}

There are studies revealing the relationship between Covid-19 related fear and behavior which is a fundamentally important connection in explaining human behavior and its underlying cognitive and emotional processing. Investigating relationships between fear of infection and hygiene behavior was accordingly done before [26]. The authors found a dose-dependent relationship between stress levels and change in behaviors due to the pandemic with an U-shaped trend: the more training medical personnel received the better they could cope with stress, but at a severe level of stress a high load of trainings would not help. Rather, the stress level would increase again [26]. While other research did find such a relationship only with training and stress but not with hygiene and fear, many studies replicated the classical Yerkes-Dodson Law in terms of such an inverted U-shaped relationship [27]. Also, it was revealed that a curvilinear relation existed between the number of behavioral recommendations and improvements in behavioral and clinical measures [28] supporting the Yerkes-Dodson Law [27]. Also, Curtis et al. (2009) concluded from their hand hygiene study "While fear of epidemics such as cholera can motivate handwashing, the motivation does not outlast the epidemic" [29].

In general, significant negative correlations were found between fear and risky health behavior with small to moderate average effect size $(r=0.22$; [30]). In other words, if more fear was perceived, fewer risky decisions were made with higher effects in nonexperimental clinical samples $(\mathrm{r}=0.33)$ than in general non-experimental and experimental studies $(r=0.15-16$; [30]). However, also testing for a curvilinear relationship revealed that fear and intention for detection behavior are both linearly and non-linearly correlated [31]. This may explain why fear can be buffered by hand hygiene behavior [32] and thereby work functionally [9]. However, whether this is the case with fear and hygiene behaviors, too, has not been systematically tested so far relating to the COVID19 pandemic (in Germany). Accordingly, the question that arise is the following:

Research Question 2: in individuals from the general population and from a sample of patients with mental health problems (i) what is the general prevalence of these hygiene behaviors, and (ii) how is the prevalence related to fears?

\section{Relationship between different health behaviors: Theoretical explanation and model}

The Compensatory Carry-Over Action Model (CCAM; [33]) builds on many other behavioral theories, which typically model single behaviors. The CCAM, however, models different single activities - such as hand hygiene and face mask wearing - and how they change also as a result of one another. Such lifestyle activities are assumed to be formed by higher-level goals (e.g., striving for life-satisfaction), which can drive activity volitionally or unconsciously, and are rather unspecific. They become specific because of behavior that is subjectively seen as leading to this goal. Each behavior must be intended, pursued, and controlled. Specific resources ensure that individuals have the chance to translate their intentions into activity and that they resist distractors.

Compensation and transfer (also called carry-over) operate between the different behaviors. If people devote all of their energy to one domain -such as avoiding mass gatherings-, and believe that no resources remain for the other activity but this one behavior actually does not require another anymore -such as keeping the distance of $1.5 \mathrm{~m}$ to other humans, because if one does not meet other individuals also no distancing is needed any more- this can reflect compensatory thinking and actions. However, as there might also be other instances to get in contact with other individuals -such as delivery at 
the apartment door even if mass gatherings are successfully avoided- a full compensation might not be possible. It would be safer from a hygiene perspective to perform both behaviors adequately. Thus, to attain both behaviors, individuals already successfully performing one activity can learn from the other behavior. The psychological mechanisms would be the transfer of existing resources (such as the self-efficacy belief) to the other behavior. Both transfer and compensation are described by the CCAM.

Different theories have been used to investigate hygiene behaviors [34,35] but no study with the CCAM could be found so far modelling hygiene behaviors. While the CCAM does not explicitly incorporate fear, it has been found that fear and life-satisfaction (as a higher-level goal) are interrelated as more fears interrelate with poorer life-satisfaction and health in patient samples [36]. In another study, behavior change in face of fear of COVID-19 was related to psychological health but not physical health [9]. As especially patients with psychological disorders such as the diagnosis of an obsessive-compulsive disorder (OCD) require special attention due to their risk of COVID-19 being a sustaining factor of the disorder or with regard to the potential risk of relapse during the period of COVID-19 pandemic relating to social restrictions and recommendations regarding hygiene behavior [37]. These outlined potential risks may also be relevant for psychosomatic patients. Questions that arise based on the CCAM are the following:

Research Question 3. To what extent are hygiene behaviors (avoiding masses, physical distancing, hand hygiene and face mask use) correlated with each other? and

Research Question 4. How do hygiene behaviors correlate with higher-level goals (life-satisfaction), change in physical and psychological health?

\section{Communication}

While individuals with disabilities may have disadvantaged chances to protect themselves from infections, communication barriers may also cause a lack of compliance to medical plans and therefore pose as a risk factor for developing secondary conditions [18]. Interpersonal communication, personnel support, structural measures, but also assertive technologies can be helpful in mitigating the increased risks and improve hygiene behavior [38]. However, as far as implementation is concerned, little can be found on this up to now and require further research.

In general, during periods of high infection rates or rising incidences, patients have avoided medical treatments [39]. Reasons include recommended movement restrictions, but also to avoid exposing themselves to the potential risk of infection. As a result, providers report concerns that patients do not seek medical care until their condition is extremely critical or that they may not seek care at all [40]. On the contrary, medical institutions have been well-prepared for treating patients even in case of resource shortage and establishing exaggerated hygiene rules in Germany [41,42]. Lund et al. call for systemic and cultural change, because prejudice and disadvantage can also result from misunderstood protective behavior (e.g., closing nursing homes for visits or not allowing residents to leave). At the same time, prejudice and stereotyping should be avoided. People who are frustrated by official measures such as curfews or school/restaurant closures possibly attribute the cause to the citizens in need of protection/assistance and accordingly shift their negative emotions to this target group [40].

With regard to possible strategies against this discrimination, it was suggested to continuously self-reflect and ensure professional self-understanding with professional development [18]. Promoting a willingness to listen and respond to the concerns and needs of 
people with disabilities is central to this. The prerequisite is informed, culturally competent clinical practice and adequate advocacy. Situational barriers that emerge in the wake of the COVID-19 pandemic, as well as long-standing systemic issues, should be considered in a holistic way. An important step with this is to take different factors into account synchronously. Thus, in addition to disability, other factors should be regarded, too: Gender differences were found in terms of women being more likely to perform hygiene behaviors than men $[2,3,7,8,10]$. In addition, age and COVID-19 experiences/ previous infections and beliefs were interrelated with the prevalence of frequent hand hygiene in $2020[8,43]$. Thus, socio-demographic variables should be controlled for as well when researching hygiene behavior but also taking disability into account [18]. A final question that arises based on the findings to date is the following:

Research Question 5: Are hygiene behaviors related to experienced communication after controlling for previous infections, disability and risk, group, anxiety, health and life-satisfaction?

The current study aims to test all five research questions in individuals from the general population and from a sample of patients with mental health problems with disabilities or with COVID-19 risk factors. The procedure will be outlined in the following.

\section{Materials and Methods}

The study was conducted as part of the two projects "Anhand-COVID19 - Offer to achieve treatment and rehabilitation goals in compliance with hygiene and social-distancing rules" (ClinicalTrials.gov Identifier: NCT04453475) and "TeamBaby - Safe, digitally supported communication in obstetrics and gynecology" (ClinicalTrials.gov Identifier: NCT03855735). Both studies with their relating data collection procedures will be described below.

\subsection{First Sample: Recruitment and Procedure of the General Population}

Data were collected anonymously through a nationwide recruitment campaign, press releases, social media posts, and the study home page of the TeamBaby project. For data collection purposes, the software tool Unipark was used. All participants were informed about the purpose of the survey beforehand and provided online informed consent. Participants were not offered any form of compensation for participation.

Data collection from the general population took place between May 2020 and August 2021. Time to complete the survey took, on average, 14.46 minutes (SD 9.47). Ethical approval for the online survey for the general population was given by the Ethics Committee at Jacobs University Bremen on September 17, 2019. The sample characteristics of the general population are reported in Table 1. 
Table 1. Characteristics of the general population (first sample) and the psychosomatic rehabilitation patients (second sample)

\begin{tabular}{|c|c|c|c|}
\hline & $\begin{array}{c}\text { General popula- } \\
\text { tion (first sample) } \\
\mathrm{N}=1894\end{array}$ & $\begin{array}{l}\text { Patients (second } \\
\text { sample) } \mathrm{N}=2155\end{array}$ & Test statistic \\
\hline Gender & & & $\operatorname{Chi}^{2}(4036,2)=23.707^{* *}$ \\
\hline Male & $563(29.7 \%)$ & $742(34.6 \%)$ & \\
\hline Female & $1312(69.3 \%)$ & $1397(65.2 \%)$ & \\
\hline Divers/other & $19(1.0 \%)$ & $3(0.1 \%)$ & \\
\hline Age $^{0}$ & & & $\operatorname{Chi}^{2}(4042,4)=529.405^{* *}$ \\
\hline$<30$ years & $441(23.3 \%)$ & $89(4.1 \%)$ & \\
\hline $30-39$ years & $426(22.5 \%)$ & $271(12.6 \%)$ & \\
\hline $40-49$ years & $374(19.7 \%)$ & $498(23.2 \%)$ & \\
\hline $50-59$ years & $393(20.7 \%)$ & $984(45.8 \%)$ & \\
\hline $60+$ years & $260(13.7 \%)$ & $306(14.2 \%)$ & \\
\hline Education (yrs schooling) & & & $\operatorname{Chi}^{2}(4014,3)=213.344^{* *}$ \\
\hline$\leq 9$ years & $189(10.0 \%)$ & $66(3.1 \%)$ & \\
\hline 10 years & $405(21.4 \%)$ & $482(22.7 \%)$ & \\
\hline 11 years & $527(27.8 \%)$ & $979(46.2 \%)$ & \\
\hline$\geq 12$ years & $773(40.8 \%)$ & $593(28.0 \%)$ & \\
\hline Working & $993(72.6 \%)$ & $1571(73.3 \%)$ & $\operatorname{Chi}^{2}(3510,1)=0.242$ \\
\hline Living with a partner/ spouse & $1148(60.0 \%)$ & $1328(61.6 \%)$ & Chi $^{2}(4049,1)=0.434$ \\
\hline Living with a child/ children & $666(35.2 \%)$ & $741(34.4 \%)$ & $\mathrm{Chi}^{2}(4049.1)=0.269$ \\
\hline COVID-19 risk factors & $424(25.3 \%)$ & $878(43.9 \%)$ & $\operatorname{Chi}^{2}(3680,1)=138.520^{* *}$ \\
\hline Disabled & $128(7.2 \%)$ & $294(13.8 \%)$ & $\operatorname{Chi}^{2}(3898,1)=43.967^{* *}$ \\
\hline Previous COVID-19 infection & $148(9.9 \%)$ & $56(3.0 \%)$ & $\operatorname{Chi}^{2}(3349,1)=68.935^{* *}$ \\
\hline Disability & $294(13.8 \%)$ & $128(7.2 \%)$ & $\operatorname{Chi}^{2}(3898,1)=43.967^{* *}$ \\
\hline $\begin{array}{l}\text { Fear of being infected with the } \\
\text { coronavirus }\end{array}$ & $2.27(1.143)$ & $2.79(1.036)$ & $\mathrm{F}(3932,1)=223.079^{* *}$ \\
\hline $\begin{array}{l}\text { Fear of getting seriously ill with } \\
\text { COVID-19 }\end{array}$ & $2.07(1.130)$ & $2.68(1.108)$ & $\mathrm{F}(3926,1)=292.766^{* *}$ \\
\hline $\begin{array}{l}\text { Fear of infecting relatives/room- } \\
\text { mates or friends with COVID-19 }\end{array}$ & $2.51(1.249)$ & $2.88(1.144)$ & $\mathrm{F}(4047,1)=98.245^{* *}$ \\
\hline Fear (Index) & $2.29(1.064)$ & $2.79(0.967)$ & $F(4047,1)=246.683^{* *}$ \\
\hline Life-satisfaction & $3.63(1.573)$ & $2.81(1.292)$ & $\mathrm{F}(4014,1)=332.900^{* *}$ \\
\hline Change in physical health & $5.23(1.991)$ & $4.89(1.848)$ & $\mathrm{F}(3964,1)=31.863^{* *}$ \\
\hline Change psychological health & $4.17(2.374)$ & $4.25(1.981)$ & $\mathrm{F}(3865,1)=1.551$ \\
\hline Comm. ${ }^{1}$ information & $4.42(1.312)$ & $4.75(1.008)$ & $\mathrm{F}(2792,1)=56.708^{* *}$ \\
\hline Comm. ${ }^{1}$ understandable & $4.35(1.364)$ & $4.72(1.040)$ & $\mathrm{F}(2794,1)=68.579^{* *}$ \\
\hline Comm. ${ }^{1}$ early enough & $3.35(1.721)$ & $4.71(1.025)$ & $\mathrm{F}(2747,1)=665.230^{* *}$ \\
\hline $\begin{array}{c}\text { Comm. }{ }^{1} \text { inclusion of accompanying } \\
\text { persons }\end{array}$ & $4.10(1.454)$ & $3.55(1.624)$ & $\mathrm{F}(2718,1)=83.845^{* *}$ \\
\hline $\begin{array}{c}\text { Comm. }{ }^{1} \text { take concerns and fears se- } \\
\text { riously }\end{array}$ & $4.06(1.432)$ & $4.51(1.166$ & $\mathrm{F}(2778,1)=83.048^{* *}$ \\
\hline Comm. ${ }^{1}$ using teach-back & $2.39(1.624)$ & $4.40(1.203)$ & $\mathrm{F}(2782,1)=1407.555^{* *}$ \\
\hline
\end{tabular}

${ }^{0}$ Age range 18-80 years; ${ }^{1}$ Comm. $=$ Communication; Mean (standard deviation in brackets)

Overall, 1894 individuals from the general population were recruited. The majority was female, above 50 years of age and with 11 years of schooling (Table 1).

\subsection{Second Sample: Recruitment and Procedure of Psychosomatic Rehabilitation Patients}

The second group of participants were recruited through four psychosomatic clinics from the Dr Becker clinic group and attended regular treatment at the recruiting clinics, consisting of psychological and physical interventions (i.e., individual and group psychotherapy, physiotherapy, or occupational therapy) as part of the incoming process for their medical rehabilitation stay. Participation was possible from six weeks before until the first 
day of medical rehabilitation treatment. Patients assigned to one of the clinics were informed about the study in writing on the hospital group's original online portal. Therefore, only patients who had access to this digital portal via smartphone, tablet, or computer before the start of rehabilitation were included.

Participation was only possible after the patients had read the participation information and had given their informed consent in writing; data were pseudonymized. Rehabilitation patients were not offered any form of compensation for their participation in the online study. Patients were invited to take part in the online survey from six weeks before until the first day of rehabilitation. The online survey at the psychosomatic clinics was administered between July 2020 and August 2021. Time to complete the survey took, on average, 22.11 minutes (SD 15.03). Ethical approval for the online survey concerning psychosomatic rehabilitation patients was given by the Ethics Committee at Jacobs University Bremen on June 25, 2020.

Overall, 2155 individuals from the patient population were recruited. The majority was female, below 40 years of age and with $12+$ years of schooling (Table 1 ).

There were significant differences between the general population sample and the patient sample in 18 out of 22 variables tested on a bivariate level (Table 1).

\subsection{Instruments}

If not differently stated in the following, all instruments were used before in a previous study published in German [48] and revealed adequate measurement qualities.

\section{Hygiene Behaviors}

Hygiene behavior in terms of hand hygiene was measured with the item "Do you wash or disinfect your hands before and after every purchase, touching door handles outside your own home, taking public transport, etc.? ". The possible response options were (1) "No, I don't intend to.", (2) “No, but I've thought about it.", (3) "No, but I've decided to do it.", (4) "Yes, but it's hard for me.", and (5) "Yes, and it's easy for me.". Answers were dichotomized as "not performing the hygiene behavior/ non-compliant" (1 to 3) or "performing the hygiene behavior/ compliant" (4 and 5).

Hygiene behavior in terms of wearing a face mask was measured with the item "Do you wear a mouth and nose protector every time you go shopping, visit hospitals and use public transportation, etc.?". The possible response options were the same as for hand hygiene. Answers were dichotomized as "not performing the hygiene behavior/non-compliant" (1 to 3) or "performing the hygiene behavior/ compliant" (4 and 5).

Hygiene behavior in terms of avoiding large masses was asked to indicate the most appropriate response to the statement "I stay away from crowded places or mass gatherings.", with the options (1) "Do not agree at all", (2) "Do rather not agree", (3) "Agree to some extent" or (4) "Agree fully". Answers were dichotomized as "not performing the hygiene behavior/ non-compliant" (1 or 2 ) or "performing the hygiene behavior/ compliant" (3 and 4).

Hygiene behavior in terms of keeping the physical distance of $1.5 \mathrm{~m}$ to other individuals was asked to indicate the most appropriate response to the statement "I keep distance (at least $1.5 \mathrm{~m}$ ) between me and other people.", with the options (1) "Do not agree at all", (2) "Do rather not agree", (3) "Agree to some extent" or (4) "Agree fully". Answers were dichotomized as "not performing the hygiene behavior/ non-compliant" (1 or 2) or "performing the hygiene behavior/ compliant" ( 3 and 4 ).

All four behaviors were aggregated in terms of a means score which revealed good internal reliability with Cronbach's Alpha $=.756$. 


\section{Fears of a SARS-COV-2 Infection and COVID-19}

Fears relating to infections with SARS-COV-2 and possible consequences of COVID-19, such as fears of being infected, fears of getting seriously ill with COVID-19, and fears of infecting close ones, such as relatives, roommates or friends, were measured by three items. All three items were assessed on a five-point Likert scale from (1) "Never", (2) "Rarely", (3) "Sometimes", (4) "Often", and (5) "Always". The items worded "How often to you fear of being infected with the coronavirus?", How often do you fear of getting seriously ill with COVID-19" and "How often to you fear of infecting relatives/roommates or friends with COVID-19". All three fear items were aggregated in terms of a means score which revealed good internal reliability with Cronbach's Alpha $=.862$.

\section{Health Outcomes}

With regard to the evaluation of health outcomes life-satisfaction, changes in physical as well as psychological health were assessed. Life-satisfaction was measured by one item: "How satisfied are you currently with your life in general". The item was assessed on a six-point Likert scale from (1) "Very dissatisfied", (2) "Dissatisfied", (3) "Somewhat dissatisfied", (4) "Somewhat satisfied", (5) "Satisfied", to (6) "Very satisfied".

Changes in physical and psychological health were both measured on an 11-point Likert scale from (1) "I feel increasingly worse", (6) "About the same", to (11) "I feel increasingly better". This was done with the two items "Has your physical health changed since the Corona crisis?" and "Has your psychological health changed since the Corona crisis?" Items were analyzed as separate outcomes. Hence, items were not aggregated as a mean score.

\section{Assessment of Healthcare Professionals Communication}

Communication of healthcare professionals was assessed by patients through six items developed based on Rider and Keefer's interpersonal communication competencies [44]. All items were measured on a six-point Likert scale form (1) "Completely disagree", (2) "Disagree", (3) "Slightly disagree", (4) "Slightly agree", (5) "Agree", to (6) "Completely agree". Items forced on the quality of information during the communication process, understandability of communicated content, early enough provision of information, inclusion of accompanying persons in the communication process, considering concerns and fears during the communication process, as well as teach-back as a communication strategy. Teach-back refers to the strategy that healthcare staff was perceived as explicitly asking recipients to repeat their explanations to ensure correct understanding. Items were analyzed separately. Hence, items were not aggregated as a mean score.

\section{Coronavirus Infection}

To examine a possible SARS-COV-2 infection, the item "Have you been infected with the coronavirus" was used. The item was measured on a 5-point Likert scale from (1) "Definitely not, the test was negative", (2) "Probably not", (3) "I don't know", (4) "Probably yes", to (5) "Definitely yes, the test was positive". Those reporting "Probably yes" or "Definitely yes, the test was positive" were considered as being infected and all others as not.

\section{Risk factors}

To assess potential health-related risk factors associated with a severe COVID-19, participants were asked whether they have underlying diseases such as cardiovascular disease, diabetes, respiratory illnesses, liver disease, kidney disease or cancer. The item was measured on a three-point Likert scale from (1) "Yes", (2) “No", to (3) "I don't know". 
In addition, a possible disability status was evaluated. Participants were asked whether they hold a card that attests them to be severely disabled. Hence, disability was measured on a three-point Likert scale from (1) "Yes", (2) "No", to (3) "I don't know". Risk factor and disability were aggregated in terms of no risk factor and disability, risk factor or disability as well as risk factor and disability.

\section{Socio-demographic characteristics}

Additional data on sociodemographic information included participants' age, sex, and educational status. Age was categorized into five groups: $\leq 29$ years, 30-39 years, 40-49 years, $50-59$ years, and $\geq 60$ years.

Sex was categorized into three groups: male, female, and diverse.

The highest obtained educational status was categorized into four groups: 10 or 11 years of schooling, 12 or more years of schooling, vocational training, and university degree.

In addition, employment status was assessed by the item "Are you currently employed? Which one applies best to your status?" which has been adapted from the German-Socio-Economic-Panel (SOEP; [45]). Those reporting "Employed full-time", "Employed part-time" or "Completing in-service training/ apprenticeship/ in-service retraining" were considered as working and all others as not working.

\subsection{Statistical Analyses}

For all analyses, SPSS Version 28 was used (IBM Corp., Armonk, NY, USA). Bivariate and multivariate statistical analyses were performed. Research question 1 was tested with a two-factorial MANOVA with the four hygiene behaviors, the three fears and the higherlevel goals (life-satisfaction), change in physical and psychological health testing for main effects but also interaction effects.

Research question 2 was tested with frequency analyses $\left(\mathrm{Chi}^{2}\right)$ and correlations analyses (Spearman's rho because hand hygiene and face mask wearing were measured in an ordinal fashion only). In addition, the trends of the interrelations were analyzed with curve estimations testing for not only the linear trend but whether furthermore quadratic and cubic trends would explain additional variance.

Research question 3 and 4 were also tested with correlations analyses (Spearman's rho). Research question 5 was tested with a binary logistic regression with a step-wise procedure.

\section{Results}

In this section, the research questions are tested with the data combined from both samples and with different analyses.

\subsection{Research Question 1: Do differences between individuals from the general population and} from a sample of patients with mental health problems with disabilities or with COVID-19 risk factors emerge in terms of (a) hygiene behaviors and (b) fear of infection as well as (c) health and life-satisfaction?

To answer the research question, a two-factorial MANOVA was run with the four hygiene behaviors, the three fears and the higher-level goals (life-satisfaction), change in physical and psychological health. Both factors were significant in terms of the patients revealing more hygiene behavior and more fears but lower physical and psychological health as well as lower life-satisfaction than the general population $\left(F_{G r o u p}(10,3635)=42.424\right.$, $\left.\mathrm{p}<.001 ; \mathrm{F}_{\text {disabilities and risk }}(20,7270)=15.026, \mathrm{p}<.001\right)$. Regarding disability and risk factors, the general trend revealed in terms of those being disabled and reporting risk factors were more likely to perform the hygiene behaviors, and displayed more fears, lower physical 
and psychological health as well as lower life-satisfaction than the ones without disability or risk factors (see appendix with all means and standard deviations).

Overall, the interaction of disability and patient group was significant, too (FInteraction $(20,7270)=2.886, p<.001)$. The group effect was significant with all test variables, while the differences regarding disabilities and risk factors were based on three hygiene behaviors (face mask, masses, physical distance), two fears (to become infected, become severely ill) as well as the change in physical health and life-satisfaction. However, the interaction was significant with hygiene behavior relating to masses (Figure 1; Finteraction $(2,4047)=2.635$, $\mathrm{p}=.015$ ), fears to infect others (Figure 2; FInteraction $(2,4047)=4.434, \mathrm{p}=.012$ ) and psychological health (Figure 3; Finteraction $(2,4047)=9.889, \mathrm{p}<.001$; for detailed means and standard deviations please see Appendix).

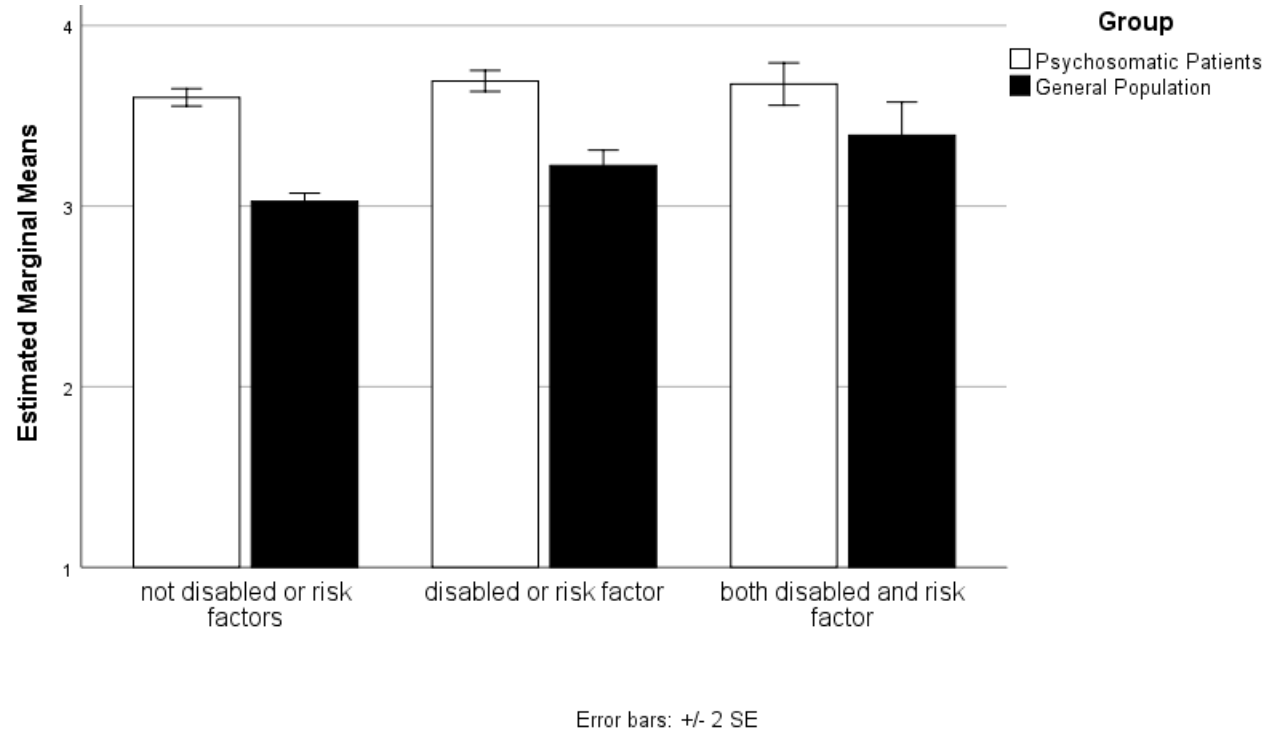

Figure 1. Reported hygiene behavior avoiding masses in patients and the general populations differentiated regarding disabilities and risk factors.

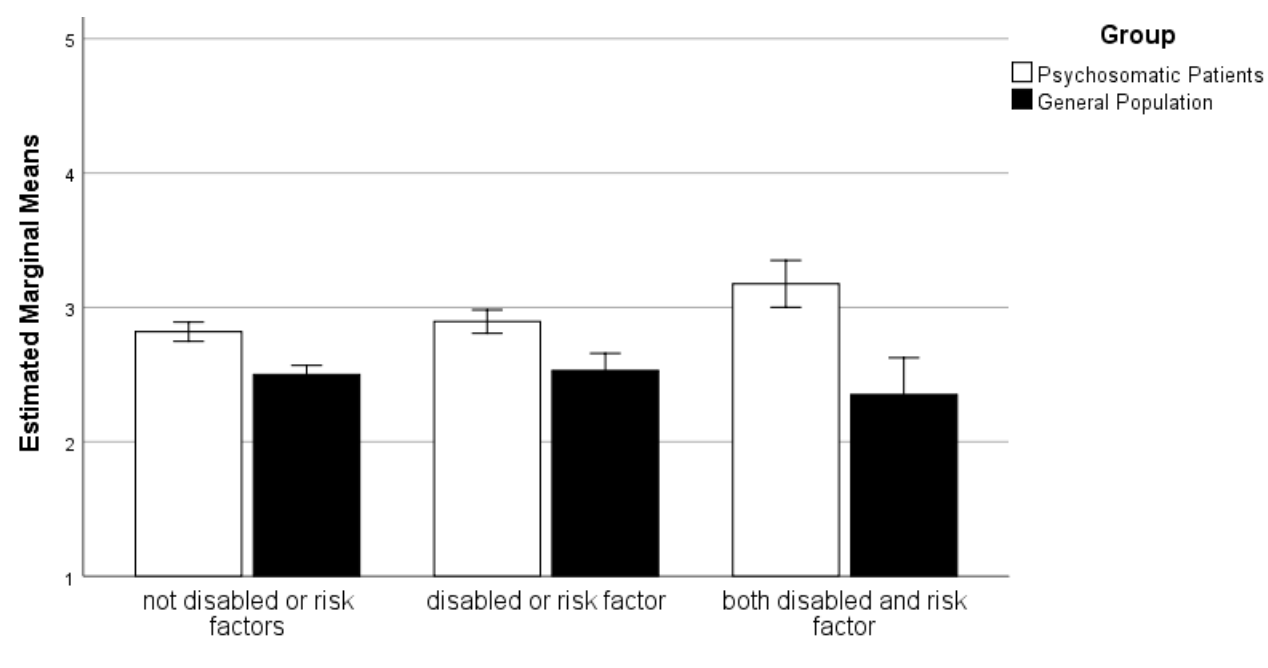

Error bars: +/- $2 \mathrm{SE}$

Figure 2. Reported fear to infect others in patients and the general populations differentiated regarding disabilities and risk factors. 


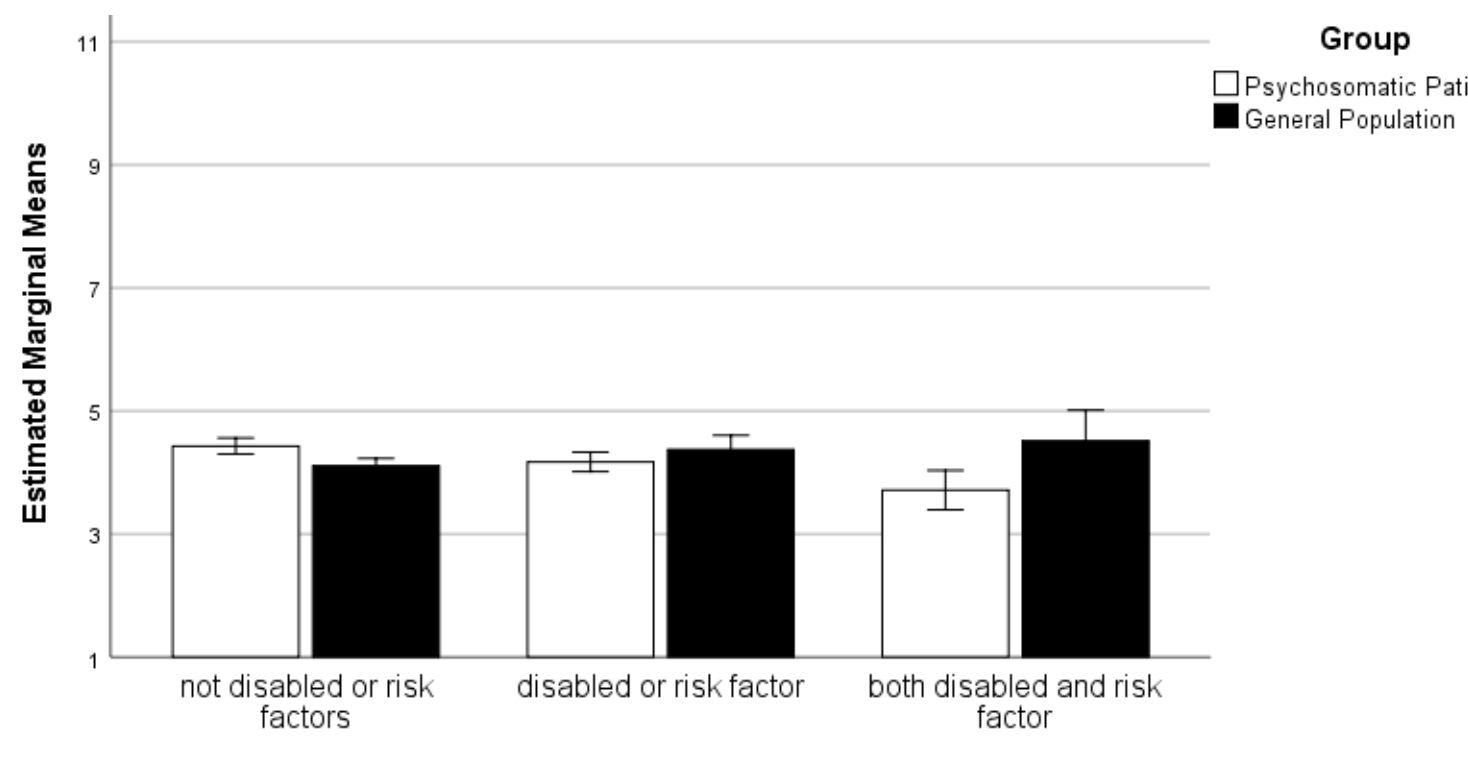

Error bars: +/- 2 SE

Figure 3. Reported improved psychological health in patients and the general populations differentiated regarding disabilities and risk factors (with the y-axis (1) "I feel increasingly worse", (6) "About the same", to (11) "I feel increasingly better").

Regarding avoiding masses, the general trend was that individuals with disability and risk factors avoided masses more than those without, and this was mainly prevalent in the general population and but not as strong in patients. The difference between patients and individuals from the general public was stronger in those with no disability and risk factors. If individuals reported disability and risk factors, patients and those from the general population appeared rather similar.

This trend was opposite with regard to fear to infect others: Here the differences were much larger in the ones with disabilities and risk factors in terms of patients exhibited a much larger fear than the individuals from the general population. However, these differences could be observed in the ones without risk factors or disability but to a smaller extent.

Remarkably, with regard to reported changes in psychological health the interaction emerged in terms of very little differences in the ones with no disability or risk factor and at least one of both. On the contrary, those with both disability and risk factors and stemming from the patient group reported much more positive changes than the general population.

3.1. Research Question 2: (i) what is the prevalence of these hygiene behaviors, and (ii) how is the prevalence related to fears?

\subsubsection{Prevalence of hygiene behaviors}

According to self-reported hand hygiene and face mask wearing, $80.7 \%$ and $96.5 \%$ of the study participants were performing the recommended hygiene behavior: Those who answered "Yes, but it's very hard for me." and "Yes, and it's very easy for me." were considered as such. However, in Table 2a the numbers of study participants with the detailed statements are reported i.e. the number of individuals stating "No, I don't intend to." (1), "No, but I've thought about it." (2), " No, but I've decided to do it." (3), "Yes, but it's very difficult for me." (4) and "Yes, and it's very easy for me." (5) with hand hygiene and face mask wearing. 
Table 2a. Prevalence of hand hygiene and face mask wearing (number of study participants, and percentages in parentheses; missing numbers to $100 \%$ are due to non-responses to these questions).

\begin{tabular}{ccc}
\hline & Hand hygiene & Face mask wearing \\
\hline No, I don't intend to. & $442(10.9 \%)$ & $111(2.7 \%)$ \\
No, but I've thought about it. & $181(4.5 \%)$ & $8(0.2 \%)$ \\
No, but I've decided to do it. & $116(2.9 \%)$ & $2(0.1 \%)$ \\
Yes, but it's hard for me. & $680(16.8 \%)$ & $1426(35.2 \%)$ \\
Yes, and it's easy for me. & $2589(63.9 \%)$ & $2483(61.3 \%)$ \\
\hline
\end{tabular}

According to self-reported avoiding large masses and keeping the physical distance of $1.5 \mathrm{~m}$ to others, $84.6 \%$ and $84.9 \%$ of the study participants were performing the recommended hygiene behavior: Those who answered "Agree to some extent." and "Agree fully." were considered as such. Accordingly, in Table $2 b$ the numbers of study participants with the detailed statements are reported i.e. the number of individuals stating that they would "Do not agree at all" (1), "Do rather not agree" (2), "Agree to some extent" (3) or "Agree fully" with avoiding large masses and keeping the distance to others (Table 2b).

Table $\mathbf{2 b}$. Prevalence of hand hygiene and face mask wearing (number of study participants, and percentages in parentheses; missing numbers to $100 \%$ are due to non-responses to these questions).

\begin{tabular}{ccc}
\hline & Avoiding large masses & $\begin{array}{c}\text { Keep the physical distance } \\
\text { of 1.5m to others }\end{array}$ \\
\hline Do not agree at all & $232(5.7 \%)$ & $143(3.5 \%)$ \\
Do rather not agree & $238(5.9 \%)$ & $321(7.9 \%)$ \\
Agree to some extent & $1210(29.9 \%)$ & $1901(46.9 \%)$ \\
Agree fully & $2216(54.7 \%)$ & $1536(37.9 \%)$ \\
\hline
\end{tabular}

3.1.2. Interrelation of hygiene behavior and fear of (a) an infection and (b) becoming severely ill and (c) infecting others.

The interrelations are reported in Table 3 showing that correlations range from .21 to .41 with all correlations being statistically significant.

Table 3. Interrelations between hygiene behaviors and fears Spearman's rho.

\begin{tabular}{lcccc}
\hline & $\begin{array}{c}\text { Hand } \\
\text { hygiene }\end{array}$ & $\begin{array}{c}\text { Face mask } \\
\text { wearing }\end{array}$ & $\begin{array}{c}\text { Avoiding } \\
\text { large masses }\end{array}$ & $\begin{array}{c}\text { Keep the physical } \\
\text { distance of 1.5m to } \\
\text { others }\end{array}$ \\
\hline $\begin{array}{c}\text { Fear of being infected with the } \\
\text { coronavirus }\end{array}$ & $.258^{* *}$ & $.235^{* *}$ & $.432^{* *}$ & $.394^{* *}$ \\
$\begin{array}{c}\text { Fear of getting seriously ill with } \\
\text { COVID-19 }\end{array}$ & $.248^{* *}$ & $.207^{* *}$ & $.410^{* *}$ & $.386^{* *}$ \\
$\begin{array}{c}\text { Fear of infecting relatives/room- } \\
\text { mates or friends with COVID-19 }\end{array}$ & $.230^{* *}$ & $.218^{* *}$ & $.333^{* *}$ & $.298^{* *}$ \\
\hline
\end{tabular}
${ }^{* *} \mathrm{p}<.001$.

Interrelations were also tested beyond the linear trend. Therefore, the four hygiene behaviors were also aggregated and the three fear items were also averaged to test for general patterns. With the aggregated hygiene behavior and the aggregated fear index, it revealed that not only linear interrelations $\left(\beta_{\text {linear }}=3.355 ; \mathrm{p}<.001\right)$ explain the variance, but 
also the quadratic term $\left(\beta_{\text {quadratic }}=-4.953 ; \mathrm{p}<.001\right)$ and the cubic terms $\left(\beta_{\text {cubic }}=2.102 ; \mathrm{p}<.001\right)$ were significant and explained $29.8 \%$ of the variance. The trends are displayed in Figure 1.

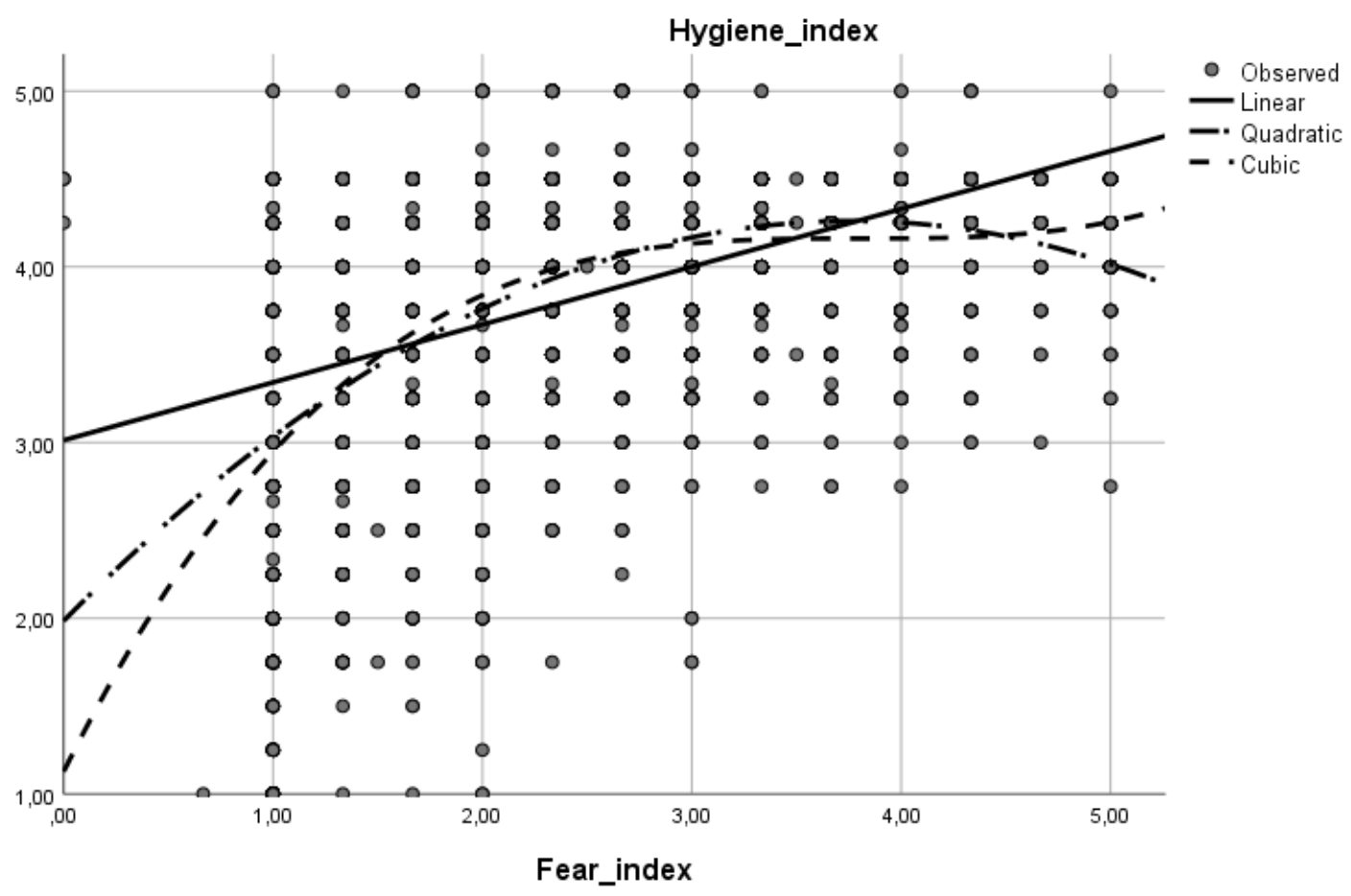

Figure 4. Interrelation of fear relating to COVID-19 infections and hygiene behaviors.

The same pattern was revealed with all individual behaviors and two fear items, namely fear of being infected with SARS-COV-2 and fear of getting seriously ill with COVID-19. However, concerning the item fear of infecting relatives/roommates or friends with COVID-19 it revealed a different pattern: While fear was significantly interrelated with hand hygiene, avoiding masses and keeping the distance in a linear and quadratic way ( $\beta$ linear $=1.043-1.313 ; p<.001 ; \beta_{\text {quadratic }}=-1.087$ to $\left.-1.473 ; p=.003-.030\right)$ the cubic trend was not significant $\left(\beta_{\text {cubic }}=0.277-0.527 ; p=.065-.343\right.$ ). Only wearing a face mask was significantly interrelated with fear in a linear, quadratic and cubic fashion $\left(\beta_{\text {linear }}=1.568 ; \mathrm{p}<.001 ; \beta_{\text {quad }}\right.$ ratic=-2.006; $\mathrm{p}<.001 ; \beta_{\text {cubic }}=0.699 ; \mathrm{p}=.017$ ).

3.2. Research Question 3: To what extent are hygiene behaviors (avoiding masses, physical distancing, hand hygiene and face mask use) correlated?

The interrelations of the different behaviors are reported in Table 4 . 
Table 4. Interrelations between hygiene behaviors and fears (Spearman's rho).

\begin{tabular}{|c|c|c|c|c|}
\hline & $\begin{array}{l}\text { Hand hy- } \\
\text { giene }\end{array}$ & $\begin{array}{c}\text { Face mask } \\
\text { wearing }\end{array}$ & $\begin{array}{c}\text { Avoiding } \\
\text { large masses }\end{array}$ & $\begin{array}{l}\text { Keep the physical dis- } \\
\text { tance of } 1.5 \mathrm{~m} \text { to others }\end{array}$ \\
\hline Hand hygiene & 1 & & & \\
\hline Face mask wearing & $.368^{* *}$ & 1 & & \\
\hline Avoiding large masses & $.364^{* *}$ & $.360^{* *}$ & 1 & \\
\hline $\begin{array}{l}\text { Keep the physical dis- } \\
\text { tance of } 1.5 \mathrm{~m} \text { to others }\end{array}$ & $.353^{* *}$ & $.314^{* *}$ & $.628^{* *}$ & 1 \\
\hline
\end{tabular}

The interrelations range from .31 to .63 with the highest interrelations between avoiding large masses and keeping the physical distance of $1.5 \mathrm{~m}$ to others while all other correlations are around .35. All correlations are statistically significant indicating that individuals who perform one hygiene behavior are more likely to also perform the other hygiene behaviors (and rather not compensate for each other).

3.3. Research Question 4: How do hygiene behaviors correlate with higher-level goals (life-satisfaction), change in physical and psychological health?

The interrelations of the hygiene behaviors and higher-level goals (life-satisfaction), change in physical and psychological health are reported in Table 5.

Table 5. Interrelations between hygiene behaviors and life-satisfaction andchange in physical and psychological health in terms of Spearman's rho.

\begin{tabular}{|c|c|c|c|c|}
\hline & $\begin{array}{l}\text { Hand hy- } \\
\text { giene }\end{array}$ & $\begin{array}{c}\text { Face mask } \\
\text { wearing }\end{array}$ & $\begin{array}{c}\text { Avoiding large } \\
\text { masses }\end{array}$ & $\begin{array}{c}\text { Keep the physical distance } \\
\text { of } 1.5 \mathrm{~m} \text { to others }\end{array}$ \\
\hline Life-satisfaction & $.048^{*}$ & $.104^{* *}$ & .019 & -.014 \\
\hline $\begin{array}{l}\text { Change in physical } \\
\text { health }\end{array}$ & $.048^{*}$ & $.119^{* *}$ & -.007 & -.022 \\
\hline $\begin{array}{l}\text { Change psycholog- } \\
\text { ical health }\end{array}$ & $.130^{* *}$ & $227^{* *}$ & $.096^{* *}$ & $.068^{* *}$ \\
\hline
\end{tabular}

While hand hygiene and face mask wearing were significantly interrelated with all three other variables, avoiding large masses and keeping the physical distance of $1.5 \mathrm{~m}$ to others was only significantly interrelated with change in psychological health: Improved psychological health was interrelated with more hygiene behaviors.

3.2. Research Question 5: Is hygiene behaviors related to experienced communication after controlling for previous infections, disability and risk, group, anxiety, health and life-satisfaction?

To test this question, hygiene behaviors were aggregated and dichotomized: Those individuals complying with all behaviors were coded as $1(\mathrm{n}=2869 ; 70.9 \%)$ and all others as 0 $(\mathrm{n}=1180 ; 29.1 \%)$. In a stepwise logistic regression, hygiene behavior was predicted firstly (in step 1) only by the reported communication. Two perceived communication strategies by health care professionals were significantly interrelated with performing all hygiene behaviors: Communication early enough and communication using teach-back. $7 \%$ of the variance was explained hereby (Table 6). 
Table 6. Models of the associated factors of hygiene behavior using binary logistic regression.

\begin{tabular}{|c|c|c|c|c|c|c|}
\hline & \multicolumn{2}{|r|}{ Step 1} & \multicolumn{2}{|r|}{ Step 2} & \multicolumn{2}{|r|}{ Step 3} \\
\hline & OR & $(95 \%$ CI) & OR & $95 \% \mathrm{CI}$ & OR & $95 \% \mathrm{CI}$ \\
\hline $\begin{array}{l}\text { Communication Infor- } \\
\text { mation }\end{array}$ & 1.084 & $(0.897 ; 1.309)$ & 1.047 & $(0.864 ; 1.269)$ & 1.096 & $(0.887 ; 1.354)$ \\
\hline $\begin{array}{l}\text { Communication Under- } \\
\text { standable }\end{array}$ & 0.921 & $(0.763 ; 1.112)$ & 0.884 & $(0.729 ; 1.072)$ & 0.901 & $(0.728 ; 1.116)$ \\
\hline $\begin{array}{l}\text { Communication early } \\
\text { enough }\end{array}$ & $1.301^{* *}$ & *(1.184; 1.429) & 1.065 & $(0.963 ; 1.178)$ & 1.045 & $(0.937 ; 1.165)$ \\
\hline $\begin{array}{c}\text { Communication Inclu- } \\
\text { sion of accompanying } \\
\text { persons }\end{array}$ & 0.944 & $(0.860 ; 1.036)$ & $1.134^{*}$ & $(1.023 ; 1.257)$ & $1.116^{*}$ & $(1.002 ; 1.243)$ \\
\hline $\begin{array}{l}\text { Communication Take } \\
\text { concerns and fears seri- } \\
\text { ously }\end{array}$ & 1.046 & $(0.917 ; 1.193)$ & 1.018 & $(0.887 ; 1.170)$ & 1.037 & $(0.892 ; 1.205)$ \\
\hline $\begin{array}{c}\text { Communication using } \\
\text { teach-back }\end{array}$ & $1.173^{* *}$ & *(1.092; 1.260) & 0.972 & $(0.894 ; 1.057)$ & 1.030 & $(0.943 ; 1.125)$ \\
\hline Risk factor & & & 0.886 & $(0.678 ; 1.156)$ & 1.187 & $(0.891 ; 1.582)$ \\
\hline Disability & & & 1.100 & $(0.739 ; 1.639)$ & 1.190 & $(0.778 ; 1.819)$ \\
\hline Group $^{1}$ & & & $0.201^{* *}$ & $(0.144 ; 0.281)$ & $0.266^{* *}$ & $*(0.187 ; 0.378)$ \\
\hline Gender $^{2}$ & & & $1.706^{*}$ & $(1.317 ; 0.208)$ & $1.350^{*}$ & $(1.025 ; 1.779)$ \\
\hline Age & & & $1.214^{* *}$ & *(1.099; 1.341) & $1.244^{* *}$ & *(1.118; 1.384) \\
\hline Schooling & & & 1.082 & $(0.952 ; 1.229)$ & 1.129 & $(0.983 ; 1.297)$ \\
\hline Covid-19 infection & & & $1.523^{*}$ & $(1.000 ; 2.336)$ & 1.532 & $(0.942 ; 2.491)$ \\
\hline Fear index & & & & & $2.686^{* *}$ & $*(2.306 ; 3.130)$ \\
\hline Nagelkerke $R^{2}$ & & .074 & & .187 & & .321 \\
\hline
\end{tabular}

${ }^{1}$ General population vs. psychosomatic rehabilitation patients; ${ }^{2}$ Gender: Male vs. female; ${ }^{* *} \mathrm{p}<.01,{ }^{*} \mathrm{p}<.001$.

In step 2 when controlling for risk factors, disability, group, socio-demographics and Covid-19 infection, however, these two communication strategies were not significant anymore but the communication strategy inclusion of accompanying persons was. Group, gender, age and a previous COVID-19 infection were significantly interrelated with hygiene behavior replicating previous findings: patients, women, older individuals and those with a previous infection were more compliant. $19 \%$ of the behavioral variance was explained.

In the 3 step, the fear index was additionally included which was significantly related to hygiene behavior, as also the communication strategy inclusion of accompanying persons was. Group, gender and age but not COVID-19 infection was significantly interrelated with hygiene behavior anymore. Overall, $32 \%$ of the behavioral variance could be explained.

In the last step (not in Table 6 included), also life-satisfaction and health were included. However, only $1 \%$ more of the variance could be explained but due to the fact that all variables were highly correlated, only patient group $(\mathrm{OR}=0.25)$ and socio-demographic variables (ORage $\left.=1.22, \mathrm{OR}_{\text {gender }}=1.36\right)$ as well as fear $(\mathrm{OR}=2.65)$ mained significantly predicting hygiene behavior.

\section{Discussion}

The current study aimed to determine factors interrelating with the hygiene behaviors relating to the COVID-19 pandemic i.e. keeping distance, avoiding masses, wearing face masks and adhering to hand hygiene recommendations by answering a number of research questions. These questions regarded how hygiene behaviors, fear of infection 
and health/ life-satisfaction depended on disabilities, the prevalence of hygiene behaviors and their association with fear, their intercorrelation as well as the correlation with higherlevel goals and experienced communication.

Summarizing the group differences concerning research question 1, we found main differences between patients and the general population but fewer differences relating to disabilities and risk factors. Psychosomatic rehabilitation patients were more compliant with regard to avoiding masses independently of their risk factors and disability status. On the contrary, individuals from the general population were much more likely to protect themselves if they had risk factors or were disabled, or were aware of both. Probably patients perceived themselves as rather vulnerable independently of whether they had specific further risk factors or disabilities. In addition, a possible explanation for the results may also be the primary diagnosis according to the International Classification of Disease - 10 Manual (ICD-10). Most patients from the rehabilitation clinics were diagnosed with either an affective disorder or an anxiety disorder. Due to the nature of those, patients usually perceive more worries and fears associated with uncertain situations which also affects their corresponding behavior [46,47].

Patients were reporting more fear to infect others with slight increases if they were aware of their own risk factors and disability. However, the opposite pattern occurred in the general population with the ones being disabled and with risk factors reporting the lowest fear. Theoretically, psychosomatic patients with risk factors or disability perceived elevated fear while individuals from the general population with own risk factors maybe had other problems to care about than to worry about infecting others. Therefore, the nearing psychosomatic rehabilitation stay with the communicated may provide an explanation for the results. As a psychosomatic rehabilitation stay is considered an in-patient stay, patients may be more aware of the potential to infect others in a new and unknown setting and with whom they have not been previously in contact with. This sense of uncertainty may consequently lead to more fears and worries associated with infecting others [48]. Additionally, the pattern in patients may relate to their diagnoses such as depression and anxiety disorder, and their inability to manage fear and stress. On the contrary, participants from the general population may have been challenged by their own risk or disability so much that they did worry less about others.

Finally, with regard to improved psychological health the pattern occurred that in patients without risk factors and disability more positive health was reported. In opposite, in the general population the ones with risk factors or/and disabilities actually improved their psychological health most over the course of the pandemic. This may also relate to the fact that patients with maximized challenges may experience more negative health developments while individuals with disabilities or risk factors from the general population may rather perceive all the hygiene measures as protective and pleasing their needs [49].

Regarding research question 2, the highest compliance rates (individuals performing the recommended hygiene behavior) could be detected with face mask wearing followed by hand hygiene. Avoiding large masses and keeping the physical distance of $1.5 \mathrm{~m}$ was performed consequently by fewer individuals. Summarizing, 81 to 97\% of participants can be considered mostly adherent. However, there was a surprisingly large number of non-intenders regarding hand hygiene $(19 \%)$ who reported that they did not adhere to hand hygiene recommendations and also had no intention to consider it. With face mask wearing, this number was much smaller with just $3 \%$.

Consequently, there is a lack of adherence to Covid-19 containment measures, especially regarding hand hygiene. This has been confirmed before in healthcare workers and the general public $[50,51]$. Reasons can be a lack of knowledge, but also other behavioral determinants [52]. However, the lack of hand hygiene can increase the spread of the SARSCoV-2 virus, so that there is a high need for adequate hand hygiene measures in the general population. In order to increase hygiene behavior, the general public needs to be informed well about the necessity but also about how hand hygiene behavior can be executed uncomplicatedly. Specific behavioral recommendations referring to how and when 
people need to disinfect or wash their hands need to be communicated. The CCAM model suggests that planning and self-efficacy can help to overcome the intention-behavior gap, which in turn can prove beneficial not only for one hygiene behavior (such as hand hygiene) but also other hygiene behaviors due to carry-over mechanisms. However, physical distancing measures such as avoiding mass gatherings or keeping a distance of $1.5 \mathrm{~m}$ can be perceived as social distancing as well. Losing social contacts can lead to increased levels of negative feelings, depression and anxiety [53]. Finding ways to stay in contact without endangering oneself to potential SARS-CoV-2 infections can be challenging but is necessary in order to remain psychologically healthy and to ensure life-satisfaction as this is the main life-goal of many individuals [54].

All hygiene behaviors were related to the fear of spreading, infecting oneself or getting seriously ill with COVID-19 in a linear and quadratic way. This indicates that after a peak, the likelihood of performing hygiene behaviors does not increase anymore. Rather, there seems to be a medium level working best while more fear is rather dysfunctional.

This finding has been termed as the Yerkes-Dodson Law [27] and can be found in all areas of behavior change. For example, successful weight loss is driven by medium levels of weight dissatisfaction. If the dissatisfaction becomes too overwhelming, individuals tend to disengage due to frustration or reactance. The same could apply to the Covid-19 pandemic. High levels of fear are sought to be avoided in order to protect the organism from excessive stress. Thus, individuals with high levels of fear are less likely to cognitively and emotionally deal with behavior change and thus abandon their efforts. This can be described well in terms of mask wearing: In our everyday life, seeing and wearing face masks have become a constant reminder of the pandemic threat, thus may work as a stimulus to elicit fear. Disengaging in mask wearing and attending mass gatherings can signal a certain "normality" that people are looking for to reduce their stress levels. Thus, stress levels should be targeted more sensibly, e.g., by using functional threat communication and positive enforcements.

On the other hand, the pandemic has been going on for more than 1.5 years already now. Thus, seeing masks and reminders to wash or disinfect hands have become more normal and individuals have become more used to pandemic cues which they might even perceive as "cue-to-action" [55]. Hand hygiene and other hygiene behaviors have been required in prior flu seasons; nevertheless, containment measures for Covid-19 are a lot more comprehensive and thus complicated. Additionally, containment measures have changed with regard to new knowledge (e.g., wearing masks outside was not required in Germany until May 2020 but was then introduced in city centers and other frequently crowded areas depending on infection rates). There is a high need to practice all behaviors adequately (so that also individuals with disabilities and risk factors such as breathing challenges can exercise them) and to find a good, individual strategy incorporating all hygiene behaviors into daily life [55].

What is promising in terms of finding a comprehensive strategy, is our result that Covid-19 hygiene behaviors were intercorrelated in our study (research question 3), especially with regard to the two physical distancing measures of avoiding masses and keeping a distance of $1.5 \mathrm{~m}$ between humans which showed a large correlation. The correlation between hand hygiene, wearing a face mask and the physical distancing measures appeared slightly lower.

As indicated above, there is a high need for all kinds of hygiene behaviors to contain the spread of the SARS-CoV-2 virus effectively. Containing the spread but also protecting one's health and quality of life i.e. life-satisfaction can be seen as higher-level goals as described in the CCAM [56]. These higher-level goals are rather unspecific, but can be achieved through different behaviors. Although each behavior must be intended and controlled individually, they also change as a result of one another. This can be promising on the one hand since a positive change in one behavior can be transferred to other behaviors. On the other hand, these carry-over mechanisms can pose a threat since non-adherence to one behavior (e.g., wearing a face mask) can negatively impact other behaviors (e.g., avoiding mass gatherings), thus leaving the individual even more vulnerable for negative 
outcomes, i.e. the increased risk of Covid-19 infections in this case. We have argued above that too much fear can inhibit positive behavior change and thus negatively impact health and life-satisfaction [9]. Although fear is not explicitly incorporated in the CCAM model, it can be explained how fear can negatively impact multiple behaviors. On the other hand, the model offers action points in terms of strengthening compensatory and transfer processes.

Regarding research question 4, life-satisfaction and a change in physical health were related to hand hygiene and face mask wearing, but not physical distancing. This may lead to reduced life-satisfaction in some people [21,22] (due to the enforced isolation or social distancing [57]) but not to everyone. However, there needs to be a clear distinction between physical and social distancing: Even while keeping a physical distance, it is possible to maintain meaningful contacts, thus avoiding social isolation and loneliness which lead to consequences such as increased levels of negative feelings, anxiety and depression. This link seems to be more pronounced in younger groups $[57,58]$ such as university students [59] since they are more dependent on contacts outside of their own household and in a more vulnerable stage of life. In our study, a substantial part of participants was older. Keeping a good hand hygiene and wearing a face mask might have helped participants to feel less vulnerable and thus support their life-satisfaction positively. The same mechanisms could explain, why all investigated hygiene behavior were significantly related to better psychological health: The ones who were able to perform the behaviors as recommended and expected were also more likely to experience more well-being. However, it could also be the other way around: Only the ones doing well were able to comply with the hygiene rules. Due to the nature of the data, the direction of the effect could not be investigated so far.

Finally, research question 5 concerning perceptions of communication and whether these were associated with hygiene behaviors. Controlling for previous infections, disability, group, anxiety, health and life-satisfaction, only the inclusion of accompanying persons showed a small significant, positive effect. Thus, it can be concluded that healthcare workers' communication style does not have a direct impact on hygiene and physical distancing behaviors but that communication is significantly interrelated with life-satisfaction and health. This can be explained in terms of pandemic risk communication. Direct communication by healthcare specialists can only inform a small number of individuals and even if done well, time restrictions greatly limit its effectiveness [60]. The mean time that is spent for a consultation in Germany is 7.6min [60], so that good communication is even more important, but at the same time limited in its value for direct behavior change. In addition, medical institutions prepared for treating patients and enforcing stricter hygiene rules [41].

Hence, more effort in research and practice needs to be focused on public risk communication. It has been established that the ongoing presence in social media, including all stakeholders and addressing risk perceptions can be helpful to target disruptive behavior over the course of a pandemic [61,62]. The World Health Organization has strongly recommended to incorporate risk communication and community engagement (RCCE) in public health emergency plans in order to prevent "infodemics" and build trust so that social disruption can be avoided and effective response can be created [63]. To ensure the applicability of RCCE in a guided fashion, checklists have been created for countries in different stages of the pandemic.

While our study sheds light on the association of hygiene behavior, Covid-19 related fear, disability and higher-level goals, several limitations regarding the sample must be borne in mind. Since the general population was assessed online and the sample of rehabilitation patients was recruited at four rehabilitation clinics, they might not be representative for the German population. However, disability has a prevalence of $9.5 \%$ in Germany, which reflects the prevalence in our sample. Additionally, the samples were recruited between May 2020 and August 2021 which is a long time during the dynamic pandemic situation. We did not control for fear and hygiene differences between Covid-19 waves and periods with lower incidences. Finally, the study was conducted with German 
samples only so that results might differ between countries and cultural contexts because Covid-19 containment measures were highly heterogeneous when regarding different contexts and regions. Our study examined the associations of Covid-19 related fears, hygiene behaviors, disability and risk factors in a cross-sectional dataset. Hence, causality changes over time could not be evaluated. In future research, more longitudinal studies as well as intervention studies [1] and more comparisons of different theories as well as more synchronized measures are required (i.e., all hygiene behaviors should be assessed with the same answering format) [1,35]. Moreover, objective data such as observations should add to the purely subjective nature of the data in this study.

Nevertheless, our study has several practical implications. Generally, individuals were more compliant if adequately aware of risks. Consequently, the public and patients should be educated well without inducing excessive levels of fear. Clear, objective RCCE should be applied by educating about risks while offering clear behavioral recommendations and strengthening self-efficacy. How to promote higher-level goals even in face of restrictions and to stay physically and mentally healthy could be emphasized. This communication may not only be done by health professionals, but also by media and authorities; thus containing the spread of the SARS-CoV-2 virus and other hygiene-related parasites.

\section{Conclusions}

In summary, we conclude that individuals who feel more vulnerable due to disabilities, physical risk factors to get (severely) ill by COVID-19 and psychological symptoms are more compliant. However, there is a (relatively) high percentage of non-compliant individuals in the general population, particularly with regard to hand hygiene measures. To promote hand hygiene and other hygiene, individuals should be carefully educated about risks ensuing from their behavior, so that a medium level of fear can be reached. If levels of fear of infecting oneself and others or getting seriously ill are either too low or too high, individuals will tend to wither disregard or avoid hygiene behaviors.

Hygiene efforts aiming at improving different behaviors in orchestration can help individuals to remain healthy and maintain a high life-satisfaction. Thus, the need and execution for hygiene behaviors should be communicated carefully also to functionally buffer the risk of being exposed to infections. Hygiene behavior should be addressed directly in order to ensure high hygiene standards and patient safety, but also indirectly in terms of being imbedded into a lifestyle approach.

Author Contributions: Conceptualization, A.D., S.L., and F.M.K..; methodology, S.L.; software, F.M.K., S.L., and A.D.; validation, A.D., S.L., and C.D.; formal analysis, S.L.; investigation, S.L., A.D., and F.M.K.; resources, A.D. and S.L.; data curation, F.M.K.; writing - original draft preparation, S.L.; writing -review and editing, F.M.K., A.D., C.D., and L.K.; visualization, S.L.; supervision, A.D.; project administration, S.L., F.M.K and A.D.; funding acquisition, S.L. and A.D. All authors have read and agreed to the published version of the manuscript.

Funding: This research was funded by the German Innovation Fund (Project No. 01VSF18023) of The Federal Joint Committee (G-BA) as part of the research project "TeamBaby - Safe, digitally supported communication in obstetrics and gynecology" (grant 01VSF18023).

Institutional Review Board Statement: The study was conducted according to the guidelines of the Declaration of Helsinki and approved by the Ethics Committee of Jacobs University Bremen (protocol code 2020_09 and date of approval: 25.06.2020).

Informed Consent Statement: Informed consent was obtained from all subjects involved in the study.

Data Availability Statement: The data presented in this study are available on request from the corresponding author. The data are not publicly available due to confidential patient data being used.

Acknowledgments: We would like to thank the Dr. Becker clinics Möhnesee, Norddeich, Juliana, and Burg for their assistance in data collection. We also appreciate the support of Kureva Matuku 
by performing parts of the literature search to review the current state of the science. Furthermore, we would like to thank Ronja Bellinghausen for proofreading this manuscript.

Conflicts of Interest: The authors declare no conflict of interest. 
Appendix A. Table with Means and Standard Deviations (in parentheses) of the test variables in patients and the general popula- 1 tion with disability or risk factor, or both or none.

\begin{tabular}{|c|c|c|c|c|}
\hline Test Variable & Disease and Disabled & Patients & General population & Total \\
\hline \multirow[t]{4}{*}{ Hand hygiene } & not disabled or risk factors & $4.60(0.820)$ & $3.67(1.667)$ & $4.11(1.414)$ \\
\hline & disabled or risk factor & $4.65(0.775)$ & $3.80(1.624)$ & $4.38(1.183)$ \\
\hline & both disabled and risk factor & r $4.58(0.760)$ & $3.92(1.469)$ & $4.39(1.057)$ \\
\hline & Total & $4.62(0.799)$ & $3.71(1.650)$ & $4.21(1.332)$ \\
\hline \multirow[t]{4}{*}{ Face mask wearing } & not disabled or risk factors & $4.77(0.421)$ & $4.33(0.931)$ & $4.54(0.767)$ \\
\hline & disabled or risk factor & $4.67(0.527)$ & $4.24(1.046)$ & $4.53(0.759)$ \\
\hline & both disabled and risk factor & r $4.60(0.491)$ & $4.26(1.194)$ & $4.50(0.777)$ \\
\hline & Total & $4.72(0.472)$ & $4.31(0.969)$ & $4.54(0.765)$ \\
\hline \multirow[t]{4}{*}{ Avoiding large masses } & not disabled or risk factors & $3.60(0.576)$ & $3.03(1.016)$ & $3.30(0.885)$ \\
\hline & disabled or risk factor & $3.69(0.501)$ & $3.22(1.023)$ & $3.54(0.742)$ \\
\hline & both disabled and risk factor & r3.68 (0.556) & $3.39(1.004)$ & $3.59(0.724)$ \\
\hline & Total & $3.64(0.549)$ & $3.08(1.022)$ & $3.39(0.843)$ \\
\hline \multirow[t]{4}{*}{ Keep the physical distance of $1.5 \mathrm{~m}$ to others } & not disabled or risk factors & $3.42(0.569)$ & $2.92(0.833)$ & $3.16(0.761)$ \\
\hline & disabled or risk factor & $3.54(0.536)$ & $3.04(0.879)$ & $3.38(0.703)$ \\
\hline & both disabled and risk factor & r $3.48(0.601)$ & $3.15(0.871)$ & $3.39(0.705)$ \\
\hline & Total & $3.47(0.563)$ & $2.96(0.847)$ & $3.24(0.748)$ \\
\hline \multirow{4}{*}{ Fear of being infected with the coronavirus } & not disabled or risk factors & $2.62(0.982)$ & $2.18(1.108)$ & $2.39(1.072)$ \\
\hline & disabled or risk factor & $2.95(1.060)$ & $2.41(1.253)$ & $2.78(1.152)$ \\
\hline & both disabled and risk factor & r $3.20(1.050)$ & $2.69(1.084)$ & $3.05(1.083)$ \\
\hline & Total & $2.79(1.037)$ & $2.25(1.146)$ & $2.55(1.120)$ \\
\hline \multirow{4}{*}{ Fear of getting seriously ill with COVID-19 } & not disabled or risk factors & $2.43(1.035)$ & $1.93(1.048)$ & $2.17(1.071)$ \\
\hline & disabled or risk factor & $2.93(1.129)$ & $2.33(1.306)$ & $2.74(1.220)$ \\
\hline & both disabled and risk factor & r3.22 (1.080) & $2.64(1.142)$ & $3.05(1.128)$ \\
\hline & Total & $2.68(1.112)$ & $2.05(1.130)$ & $2.40(1.163)$ \\
\hline \multirow[t]{4}{*}{ Fear of infecting relatives/ roommates or friends with COVID-19 } & 9 not disabled or risk factors & $2.82(1.072)$ & $2.50(1.228)$ & $2.65(1.167)$ \\
\hline & disabled or risk factor & $2.89(1.192)$ & $2.53(1.284)$ & $2.78(1.233)$ \\
\hline & both disabled and risk factor & r $3.18(1.245)$ & $2.35(1.078)$ & $2.94(1.254)$ \\
\hline & Total & $2.88(1.137)$ & $2.50(1.233)$ & $2.71(1.196)$ \\
\hline \multirow[t]{4}{*}{ Change in physical health } & not disabled or risk factors & $5.09(1.783)$ & $5.26(1.946)$ & $5.18(1.872)$ \\
\hline & disabled or risk factor & $4.72(1.831)$ & $5.15(2.133)$ & $4.85(1.941)$ \\
\hline & both disabled and risk factor & r $4.62(2.088)$ & $4.96(1.940)$ & $4.71(2.049)$ \\
\hline & Total & $4.91(1.839)$ & $5.22(1.987)$ & $5.05(1.913)$ \\
\hline \multirow[t]{2}{*}{ Change psychological health } & not disabled or risk factors & $4.43(1.997)$ & $4.11(2.289)$ & $4.26(2.161)$ \\
\hline & disabled or risk factor & $4.17(1.945)$ & $4.37(2.608)$ & $4.24(2.178)$ \\
\hline
\end{tabular}




\section{References}

1. Gaube, S.; Fischer, P.; Windl, V.; Lermer, E. The effect of persuasive messages on hospital visitors' hand hygiene behavior. Health Psychol. 2020, 39, 471-481, doi:10.1037/hea0000854.

2. Abdelrahman, M. Personality Traits, Risk Perception, and Protective Behaviors of Arab Residents of Qatar During the COVID-19 Pandemic. Int. J. Ment. Health Addict. 2020, 1-12, doi:10.1007/s11469-020-00352-7.

3. Zickfeld, J.H.; Schubert, T.W.; Herting, A.K.; Grahe, J.; Faasse, K. Correlates of Health-Protective Behavior During the Initial Days of the COVID-19 Outbreak in Norway. Front. Psychol. 2020, 11, 564083, doi:10.3389/fpsyg.2020.564083.

4. Mardiko, A.A.; Lengerke, T. von. When, how, and how long do adults in Germany self-reportedly wash their hands? Compliance indices based on handwashing frequency, technique, and duration from a cross-sectional representative survey. Int. J. Hyg. Environ. Health 2020, 230, 113590, doi:10.1016/j.ijheh.2020.113590.

5. Hommes, F.; van Loon, W.; Thielecke, M.; Abramovich, I.; Lieber, S.; Hammerich, R.; Gehrke-Beck, S.; Linzbach, E.; Schuster, A.; Busche, K. von dem; et al. SARS-CoV-2 Infection, Risk Perception, Behaviour and Preventive Measures at Schools in Berlin, Germany, during the Early Post-Lockdown Phase: A Cross-Sectional Study. Int. J. Environ. Res. Public Health 2021, 18, doi:10.3390/ijerph18052739.

6. Eichenberg, C.; Grossfurthner, M.; Andrich, J.; Hübner, L.; Kietaibl, S.; Holocher-Benetka, S. The Relationship Between the Implementation of Statutory Preventative Measures, Perceived Susceptibility of COVID-19, and Personality Traits in the Initial Stage of Corona-Related Lockdown: A German and Austrian Population Online Survey. Front. Psychiatry 2021, 12, 596281, doi:10.3389/fpsyt.2021.596281.

7. Magnan, R.E.; Gibson, L.P.; Bryan, A.D. Cognitive and Affective Risk Beliefs and their Association with Protective Health Behavior in Response to the Novel Health Threat of COVID-19. J. Behav. Med. 2021, 44, 285-295, doi:10.1007/s10865-021-00202-4.

8. Czeisler, M.É.; Garcia-Williams, A.G.; Molinari, N.-A.; Gharpure, R.; Li, Y.; Barrett, C.E.; Robbins, R.; FacerChilds, E.R.; Barger, L.K.; Czeisler, C.A.; et al. Demographic Characteristics, Experiences, and Beliefs Associated with Hand Hygiene Among Adults During the COVID-19 Pandemic - United States, June 24-30, 2020. MMWR Morb. Mortal. Wkly. Rep. 2020, 69, 1485-1491, doi:10.15585/mmwr.mm6941a3.

9. Harper, C.A.; Satchell, L.P.; Fido, D.; Latzman, R.D. Functional Fear Predicts Public Health Compliance in the COVID-19 Pandemic. Int. J. Ment. Health Addict. 2020, 1-14, doi:10.1007/s11469-020-00281-5.

10. Yıldırım, M.; Geçer, E.; Akgül, Ö. The impacts of vulnerability, perceived risk, and fear on preventive behaviours against COVID-19. Psychol. Health Med. 2021, 26, 35-43, doi:10.1080/13548506.2020.1776891.

11. Bulmash, B.; Ben-Assuli, O.; Amar, M. Fear of Hospital-Acquired Infections: The Combined Impact of Patient's Hygiene Sensitivity and Perceived Staff Preventive Behavior. J. Community Health 2020, 45, 1211-1219, doi:10.1007/s10900-020-00857-1.

12. Apisarnthanarak, A.; A pisarnthanarak, P.; Siripraparat, C.; Saengaram, P.; Leeprechanon, N.; Weber, D.J. Impact of anxiety and fear for COVID-19 toward infection control practices among Thai healthcare workers. Infect. Control Hosp. Epidemiol. 2020, 41, 1093-1094, doi:10.1017/ice.2020.280.

13. Blagov, P.S. Adaptive and Dark Personality in the COVID-19 Pandemic: Predicting Health-Behavior Endorsement and the Appeal of Public-Health Messages. Social Psychological and Personality Science 2021, 12, 697707, doi:10.1177/1948550620936439.

14. Tsamakis, K.; Triantafyllis, A.S.; Tsiptsios, D.; Spartalis, E.; Mueller, C.; Tsamakis, C.; Chaidou, S.; Spandidos, D.A.; Fotis, L.; Economou, M.; et al. COVID-19 related stress exacerbates common physical and mental pathologies and affects treatment (Review). Exp. Ther. Med. 2020, 20, 159-162, doi:10.3892/etm.2020.8671. 
15. Gallagher, M.W.; Zvolensky, M.J.; Long, L.J.; Rogers, A.H.; Garey, L. The Impact of Covid-19 Experiences and Associated Stress on Anxiety, Depression, and Functional Impairment in American Adults. Cognit. Ther. Res. 2020, 1-9, doi:10.1007/s10608-020-10143-y.

16. Rubin, G.J.; Potts, H.W.W.; Michie, S. The impact of communications about swine flu (influenza A H1N1v) on public responses to the outbreak: results from 36 national telephone surveys in the UK. Health Technol. Assess. 2010, 14, 183-266, doi:10.3310/hta14340-03.

17. van der Valk, J.P.M.; Heijboer, F.W.J.; van Middendorp, H.; Evers, A.W.M.; Veen, J.C.C.M. in 't. Case-control study of patient characteristics, knowledge of the COVID-19 disease, risk behaviour and mental state in patients visiting an emergency room with COVID-19 symptoms in the Netherlands. PLoS One 2021, 16, e0249847, doi:10.1371/journal.pone.0249847.

18. Sharby, N.; Martire, K.; Iversen, M.D. Decreasing health disparities for people with disabilities through improved communication strategies and awareness. Int. J. Environ. Res. Public Health 2015, 12, 3301-3316, doi:10.3390/ijerph120303301.

19. Nachtigall, I.; Lenga, P.; Jóźwiak, K.; Thürmann, P.; Meier-Hellmann, A.; Kuhlen, R.; Brederlau, J.; Bauer, T.; Tebbenjohanns, J.; Schwegmann, K.; et al. Clinical course and factors associated with outcomes among 1904 patients hospitalized with COVID-19 in Germany: an observational study. Clin. Microbiol. Infect. 2020, 26, 16631669, doi:10.1016/j.cmi.2020.08.011.

20. Hollis, N.D.; Thierry, J.M.; Garcia-Williams, A.G. Self-reported handwashing and surface disinfection behaviors by U.S. adults with disabilities to prevent COVID-19, Spring 2020. Disabil. Health J. 2021, 14, 101096, doi:10.1016/j.dhjo.2021.101096.

21. Balkhi, F.; Nasir, A.; Zehra, A.; Riaz, R. Psychological and Behavioral Response to the Coronavirus (COVID-19) Pandemic. Cureus 2020, 12, e7923, doi:10.7759/cureus.7923.

22. Rogers, J.P.; Chesney, E.; Oliver, D.; Pollak, T.A.; McGuire, P.; Fusar-Poli, P.; Zandi, M.S.; Lewis, G.; David, A.S. Psychiatric and neuropsychiatric presentations associated with severe coronavirus infections: a systematic review and meta-analysis with comparison to the COVID-19 pandemic. The Lancet Psychiatry 2020, 7, 611-627, doi:10.1016/S2215-0366(20)30203-0.

23. van Rheenen, T.E.; Meyer, D.; Neill, E.; Phillipou, A.; Tan, E.J.; Toh, W.L.; Rossell, S.L. Mental health status of individuals with a mood-disorder during the COVID-19 pandemic in Australia: Initial results from the COLLATE project. J. Affect. Disord. 2020, 275, 69-77, doi:10.1016/j.jad.2020.06.037.

24. Fiorillo, A.; Gorwood, P. The consequences of the COVID-19 pandemic on mental health and implications for clinical practice. Eur. Psychiatry 2020, 63, e32, doi:10.1192/j.eurpsy.2020.35.

25. Habermann-Horstmeier; L. COVID-19 cases and fatality rates in facilities for people with disabilities in BadenWürttemberg, Germany - compared to data from Sweden, the Netherlands and the USA. (COVID-19-Fallzahlen und Sterberaten in Behinderteneinrichtungen in Baden-Württemberg. Ein Vergleich mit Daten aus Schweden, den Niederlanden und den USA.), 2020.

26. Ammar, N.; Aly, N.M.; Folayan, M.O.; Khader, Y.; Virtanen, J.I.; Al-Batayneh, O.B.; Mohebbi, S.Z.; Attia, S.; Howaldt, H.-P.; Boettger, S.; et al. Behavior change due to COVID-19 among dental academics-The theory of planned behavior: Stresses, worries, training, and pandemic severity. PLoS One 2020, 15, e0239961, doi:10.1371/journal.pone.0239961.

27. Yerkes, R.M.; Dodson, J.D. The relation of strength of stimulus to rapidity of habit-formation. J. Comp. Neurol. Psychol. 1908, 18, 459-482, doi:10.1002/cne.920180503.

28. Wilson, K.; Senay, I.; Durantini, M.; Sánchez, F.; Hennessy, M.; Spring, B.; Albarracín, D. When it comes to lifestyle recommendations, more is sometimes less: a meta-analysis of theoretical assumptions underlying the 
effectiveness of interventions promoting multiple behavior domain change. Psychol. Bull. 2015, 141, 474-509, doi:10.1037/a0038295.

29. Curtis, V.A.; Danquah, L.O.; Aunger, R.V. Planned, motivated and habitual hygiene behaviour: an eleven country review. Health Educ. Res. 2009, 24, 655-673, doi:10.1093/her/cyp002.

30. Wake, S.; Wormwood, J.; Satpute, A.B. The influence of fear on risk taking: a meta-analysis. Cogn. Emot. 2020, 34, 1143-1159, doi:10.1080/02699931.2020.1731428.

31. Dillard, J.P.; Li, R.; Huang, Y. Threat Appeals: The Fear-Persuasion Relationship is Linear and Curvilinear. Health Commun. 2017, 32, 1358-1367, doi:10.1080/10410236.2016.1220345.

32. Trougakos, J.P.; Chawla, N.; McCarthy, J.M. Working in a pandemic: Exploring the impact of COVID-19 health anxiety on work, family, and health outcomes. J. Appl. Psychol. 2020, 105, 1234-1245, doi:10.1037/apl0000739.

33. Lippke, S.; Dahmen, A.; Gao, L.; Guza, E.; Nigg, C.R. To What Extent is Internet Activity Predictive of Psychological Well-Being? Psychol. Res. Behav. Manag. 2021, 14, 207-219, doi:10.2147/PRBM.S274502.

34. Gaube, S.; Fischer, P.; Lermer, E. Hand(y) hygiene insights: Applying three theoretical models to investigate hospital patients' and visitors' hand hygiene behavior. PLoS One 2021, 16, e0245543, doi:10.1371/journal.pone.0245543.

35. Lin, C.-Y.; Imani, V.; Majd, N.R.; Ghasemi, Z.; Griffiths, M.D.; Hamilton, K.; Hagger, M.S.; Pakpour, A.H. Using an integrated social cognition model to predict COVID-19 preventive behaviours. Br. J. Health Psychol. 2020, 25, 981-1005, doi:10.1111/bjhp.12465.

36. Buunk-Werkhoven, Y.A.B.; Dijkstra, A.; van der Schans, C.P. Oral Health-Quality of Life Predictors Depend on Population. Applied Research Quality Life 2009, 4, 283-293, doi:10.1007/s11482-009-9081-y.

37. Davide, P.; Andrea, P.; Martina, O.; Andrea, E.; Davide, D.; Mario, A. The impact of the COVID-19 pandemic on patients with OCD: Effects of contamination symptoms and remission state before the quarantine in a preliminary naturalistic study. Psychiatry Res. 2020, 291, 113213, doi:10.1016/j.psychres.2020.113213.

38. Andrade, E.L.; Bingenheimer, J.B.; Edberg, M.C.; Zoerhoff, K.L.; Putzer, E.M. Evaluating the effectiveness of a community-based hygiene promotion program in a rural Salvadoran setting. Glob. Health Promot. 2019, 26, 69-80, doi:10.1177/1757975917695072.

39. Keller, F.M.; Dahmen, A.; Derksen, C.; Kötting, L.; Lippke, S. Implementing Digital Trainings within Medical Rehabilitations: Improvement of Mental Health and Synergetic Outcomes with Healthcare Service. IJERPH 2021, 18, 8936, doi:10.3390/ijerph18178936.

40. Lund, E.M.; Forber-Pratt, A.J.; Wilson, C.; Mona, L.R. The COVID-19 pandemic, stress, and trauma in the disability community: A call to action. Rehabil. Psychol. 2020, 65, 313-322, doi:10.1037/rep0000368.

41. Scheidt-Nave, C.; Barnes, B.; Beyer, A.-K.; Busch, M.; Hapke, U.; Heidemann, C.; Imhoff, M.; Mumm, R.; Paprott, R.; Steppuhn, H.; et al. Versorgung von chronisch Kranken in Deutschland - Herausforderungen in Zeiten der COVID-19-Pandemie 2020, doi:10.25646/7167.

42. Marckmann, G.; Neitzke, G.; Schildmann, J.; Michalsen, A.; Dutzmann, J.; Hartog, C.; Jöbges, S.; Knochel, K.; Michels, G.; Pin, M.; et al. Entscheidungen über die Zuteilung intensivmedizinischer Ressourcen im Kontext der COVID-19-Pandemie : Klinisch-ethische Empfehlungen der DIVI, der DGINA, der DGAI, der DGIIN, der DGNI, der DGP, der DGP und der AEM. Med. Klin. Intensivmed. Notfmed. 2020, 115, 477-485, doi:10.1007/s00063-02000708-w.

43. Huang, Q.; Luo, L.-S.; Wang, Y.-Y.; Jin, Y.-H.; Zeng, X.-T. Gender Differences in Psychological and Behavioral Responses of Infected and Uninfected Health-Care Workers During the Early COVID-19 Outbreak. Front. Public Health 2021, 9, 638975, doi:10.3389/fpubh.2021.638975.

44. Rider, E.A.; Keefer, C.H. Communication skills competencies: definitions and a teaching toolbox. Med. Educ. 2006, 40, 624-629, doi:10.1111/j.1365-2929.2006.02500.x. 
45. Goebel, J.; Grabka, M.M.; Liebig, S.; Kroh, M.; Richter, D.; Schröder, C.; Schupp, J. The German Socio-Economic Panel (SOEP). Jahrbücher für Nationalökonomie und Statistik 2019, 239, 345-360, doi:10.1515/jbnst-2018-0022.

46. Watkins, E.; Moulds, M.; Mackintosh, B. Comparisons between rumination and worry in a non-clinical population. Behav. Res. Ther. 2005, 43, 1577-1585, doi:10.1016/j.brat.2004.11.008.

47. American Psychiatric Association. Diagnostic and Statistical Manual of Mental Disorders; American Psychiatric Association, 2013, ISBN 0-89042-555-8.

48. Dahmen, A.; Keller, F.; Kötting, L.; Derksen, C.; Lippke, S. Angst vor dem Coronavirus, Absicht zum Befolgen der AHA-Regeln und Risikowahrnehmung bezüglich Arztbesuchen: Querschnittsstudie mit psychisch vorerkrankten Menschen. Gesundheitswesen 2021, 83, 274-281, doi:10.1055/a-1397-7214.

49. Okoro, C.A.; Strine, T.W.; McKnight-Eily, L.; Verlenden, J.; Hollis, N.D. Indicators of poor mental health and stressors during the COVID-19 pandemic, by disability status: A cross-sectional analysis. Disabil. Health J. 2021, 101110, doi:10.1016/j.dhjo.2021.101110.

50. McDonald, M.V.; Brickner, C.; Russell, D.; Dowding, D.; Larson, E.L.; Trifilio, M.; Bick, I.Y.; Sridharan, S.; Song, J.; Adams, V.; et al. Observation of Hand Hygiene Practices in Home Health Care. J. Am. Med. Dir. Assoc. 2021, 22, 1029-1034, doi:10.1016/j.jamda.2020.07.031.

51. Jabbari, P.; Taraghikhah, N.; Jabbari, F.; Ebrahimi, S.; Rezaei, N. Adherence of the General Public to SelfProtection Guidelines During the COVID-19 Pandemic. Disaster Med. Public Health Prep. 2020, 1-4, doi:10.1017/dmp.2020.445.

52. Derksen, C.; Keller, F.M.; Lippke, S. Obstetric Healthcare Workers' Adherence to Hand Hygiene Recommendations during the COVID-19 Pandemic: Observations and Social-Cognitive Determinants. Appl. Psychol. Health Well Being 2020, 12, 1286-1305, doi:10.1111/aphw.12240.

53. Cacioppo, J.T.; Cacioppo, S. Social Relationships and Health: The Toxic Effects of Perceived Social Isolation. Soc. Personal. Psychol. Compass 2014, 8, 58-72, doi:10.1111/spc3.12087.

54. Lippke, S.; Fischer, M.A.; Ratz, T. Physical Activity, Loneliness, and Meaning of Friendship in Young Individuals - A Mixed-Methods Investigation Prior to and During the COVID-19 Pandemic With Three Cross-Sectional Studies. Front. Psychol. 2021, 12, 617267, doi:10.3389/fpsyg.2021.617267.

55. Tong, K.K.; Chen, J.H.; Yu, E.W.-Y.; Wu, A.M.S. Adherence to COVID-19 Precautionary Measures: Applying the Health Belief Model and Generalised Social Beliefs to a Probability Community Sample. Appl. Psychol. Health Well Being 2020, 12, 1205-1223, doi:10.1111/aphw.12230.

56. Tan, S.L.; Storm, V.; Reinwand, D.A.; Wienert, J.; Vries, H. de; Lippke, S. Understanding the Positive Associations of Sleep, Physical Activity, Fruit and Vegetable Intake as Predictors of Quality of Life and Subjective Health Across Age Groups: A Theory Based, Cross-Sectional Web-Based Study. Front. Psychol. 2018, 9, 977, doi:10.3389/fpsyg.2018.00977.

57. Knopf, A. Prepare for increased depression, anxiety in youth due to COVID-19 lockdown. The Brown University Child E Adolescent Psychopharmacology Update 2020, 22, 1-4, doi:10.1002/cpu.30511.

58. Lippke, S.; Keller, F.; Derksen, C.; Kötting, L.; Ratz, T.; Fleig, L. Einsam(er) seit der Coronapandemie: Wer ist besonders betroffen? - psychologische Befunde aus Deutschland. Präv Gesundheitsf 2021, doi:10.1007/s11553-02100837-w.

59. Volken, T.; Zysset, A.; Amendola, S.; Klein Swormink, A.; Huber, M.; Wyl, A. von; Dratva, J. Depressive Symptoms in Swiss University Students during the COVID-19 Pandemic and Its Correlates. Int. J. Environ. Res. Public Health 2021, 18, doi:10.3390/ijerph18041458.

60. Deveugele, M.; Derese, A.; van den Brink-Muinen, A.; Bensing, J.; Maeseneer, J. de. Consultation length in general practice: cross sectional study in six European countries. BMJ 2002, 325, 472, doi:10.1136/bmj.325.7362.472. 
61. Lohiniva, A.-L.; Sane, J.; Sibenberg, K.; Puumalainen, T.; Salminen, M. Understanding coronavirus disease (COVID-19) risk perceptions among the public to enhance risk communication efforts: a practical approach for outbreaks, Finland, February 2020. Euro Surveill. 2020, 25, doi:10.2807/1560-7917.ES.2020.25.13.2000317.

62. Abrams, E.M.; Greenhawt, M. Risk Communication During COVID-19. J. Allergy Clin. Immunol. Pract. 2020, 8 , 1791-1794, doi:10.1016/j.jaip.2020.04.012.

63. World Health Organization. Risk communication and community engagement readiness and response to coronavirus disease (COVID-19): interim guidance, 19 March 2020 (No. WHO/2019-nCoV/RCCE/2020.2). Available online: https://apps.who.int/iris/bitstream/handle/10665/331513/WHO-2019-nCoV-RCCE-2020.2eng.pdf (accessed on 31 August 2021). 